\title{
Changes in Perceptions and Use of Mobile Technology and Health Communication in South Africa During the COVID-19 Lockdown: Cross-sectional Survey Study
}

Alex Emilio Fischer ${ }^{1}$, BSc, MPH; Tanya Van Tonder ${ }^{2}$, BA; Siphamandla B Gumede ${ }^{1}$, MSc; Samanta T Lalla-Edward ${ }^{1}$, $\mathrm{PhD}$

${ }^{1}$ Ezintsha, Faculty of Health Sciences, University of Witwatersrand, Johannesburg, South Africa

${ }^{2}$ Opinion Solutions, Johannesburg, South Africa

Corresponding Author:

Alex Emilio Fischer, BSc, MPH

Ezintsha

Faculty of Health Sciences

University of Witwatersrand

Sunnyside Office Park

31 Princess of Wales Terrace Parktown

Johannesburg, 2193

South Africa

Phone: 270737762705

Email: fischermHealth@gmail.com

\begin{abstract}
Background: In late March 2020, South Africa implemented a 5-stage COVID-19 Risk Adjusted Strategy, which included a lockdown that required all residents to remain home to prevent the spread of COVID-19. Due to this lockdown, individuals have been forced to find and use alternatives for accomplishing tasks including shopping, socializing, working, and finding information, and many have turned to the internet and their mobile devices.
\end{abstract}

Objective: This study aimed to describe how South Africans consume and internalize information surrounding the COVID-19 outbreak in order to determine whether the COVID-19 lockdown and social isolation have influenced technology behavior, particularly in terms of health communication and information.

Methods: From June 24 to August 24, 2020, people in South Africa were invited to complete a survey through the Upinion mobile app, an online data collection resource. The survey collected information on demographics, and technology use during the lockdown, and COVID-19 knowledge.

Results: There were 405 participants, of which $296(73.06 \%)$ were female. A total of $320(79.01 \%)$ participants had a tertiary school education, 242 (59.75\%) were single, and 173 (42.72\%) had full-time employment. The lockdown forced $363(89.63 \%)$ participants to use more technology, especially for work $(n=140,24.05 \%)$ and social media/communication $(n=133,22.85 \%)$. Security or privacy issues $(n=46,38.98 \%)$ and unfamiliarity with technology $(n=32,27.12 \%)$ were identified as the most common issues faced by the $127(31.36 \%)$ participants who were unsure about using technology prior to the lockdown. Almost all participants $(\mathrm{n}=392,96.79 \%)$ stated that they would continue using technology after the lockdown. Multimedia ( $\mathrm{n}=215,53.09 \%)$, mobile phone content $(n=99,24.44 \%)$, and health organizations and professionals $(n=91,22.47 \%)$ were the main sources of COVID-19 information. Most participants $(n=282,69.63 \%)$ felt that they had enough information. Two-thirds $(n=275,67.90 \%)$ of participants stated that they had used their mobile phones for health information before the lockdown, with web searches $(n=109,26.91 \%)$, social media $(n=58,14.32 \%)$, and government and institutional websites $(n=52 ; 12.84 \%)$ serving as their main sources of information. Overall, the mean COVID-19 knowledge score was 8.8 (out of 10), and 335 (82.72\%) had adequate knowledge (scored $\geq 8$ ). Males were less likely to identify the correct transmission routes, and single participants were less likely to identify the signs and symptoms of the coronavirus. Tertiary school graduates were 4 times more likely to correctly identify the routes and 2 times more likely to identify how to stop the spread of the virus. People aged 43-56 years were 4 times more likely to identify how the coronavirus can be prevented, and participants $\geq 57$ years were 2.6 times more likely to obtain a knowledge score of 10 when compared to those under 29 years of age. 
Conclusions: This study has shown that the COVID-19 lockdown has forced people to increase technology use, and people plan to continue using technology after the lockdown is lifted. Increased technology use was seen across a variety of fields; however, barriers including privacy, unfamiliarity, and data costs were identified. This population showed high COVID-19 knowledge, although the use of web searches and social media, instead of government and institutional websites, increases the potential for health misinformation to be spread.

(JMIR Form Res 2021;5(5):e25273) doi: 10.2196/25273

\section{KEYWORDS}

coronavirus; SARS-CoV-2; COVID-19; technology; mHealth; app

\section{Introduction}

On March 11, 2020, the World Health Organization declared the COVID-19 outbreak a pandemic [1]; thereafter, many countries followed China's "lockdown" approach to reduce new cases. In March 2020, South Africa began a 21-day, level 5 lockdown as part of a 5-stage COVID-19 Risk Adjusted Strategy. During this period, only hospitals, clinics, grocery stores, and pharmacies remained open, and only essential personnel (eg, doctors, nurses, police) were permitted to leave their homes, although there were some controlled exceptions for medical care or essential supplies like food and medicine [2].

During the lockdown, cases and preventative measures have been well documented and investigated, both globally and in South Africa [3,4]. However, the behavioral effects of the lockdown are not as well known. With social distancing, individuals have been forced to find and use alternatives to accomplish tasks such as shopping, working, attending school, and staying informed, and many have turned to their mobile devices. In China there was a $30 \%$ increase in app use during their lockdown [5-7], while a global analysis of five popular social media platforms (Twitter, Instagram, YouTube, Reddit, and Gab) identified 8 million COVID-19-related posts and comments over the first 45 days of 2020 [8].

In a sense, this is all forced use of technology since people have limited alternatives to meet their needs, and to engage with this captive audience, many governments and institutions have introduced mobile health (mHealth) interventions to disseminate information during the pandemic [9-12]. Specifically, the South African government has implemented a website that provides information on COVID-19, the Risk Adjusted Strategy, preventative measures, news and updates, and links to other resources [13]. These additional resources include a WhatsApp support line, an emergency telehealth hotline, social media message campaigns, and updates from the South African Government and National Department of Health websites $[3,13,14]$.

With all of this electronic communication resulting from COVID-19, researchers have taken the opportunity to investigate how it has influenced digital health, and a variety of studies have already been conducted. Some studies have harnessed big data to predict outbreak hotspots with algorithm-based web mining [8,15-17], while others have looked at how individuals share and consume COVID-19-related content [18]. A study from India showed that more than half of participants $(n=58$,
$56.3 \%$ ) had adequate information regarding COVID-19; however, their primary source of information was from multimedia (radio, TV, newspaper) $(\mathrm{n}=57,55.3 \%)$, and only $22(21.4 \%)$ relied on the internet as their main source for information [19].

Despite high mobile penetration in low- and middle-income countries [20,21], there are still individuals who have not embraced technology for various reasons, including security and privacy concerns, data costs, and an inability to understand modern electronics [22]. With the limitations set by the lockdown, increased exposure to technology may have altered some people's perceptions and use of technology. This study aimed to describe how South Africans consume and internalize information surrounding the COVID-19 outbreak to assess whether the COVID-19 lockdown and social isolation has influenced technology behavior, particularly for health communication and information.

\section{Methods}

\section{Study Design}

This South African cross-sectional study was conducted electronically, administered through the Upinion mobile app, an online data collection resource. Participants were included if they were an existing or new Upinion user with current access to surveys on the app, $\geq 18$ years of age, and able to provide online consent. Individuals were excluded if they were not able to access the Upinion app, were younger than 18 years, or refused to participate.

\section{Data Collection}

From June 24 to August 24, 2020, existing and new Upinion users were invited to complete a survey through Upinion notifications and advertisements on social media platforms, respectively. Once an individual agreed to participate in the current study, they were able to provide informed consent through the app and then register for the survey group [23]. The participant was then given access to the survey, which was completed through their mobile phone. During the survey, all answers were recorded electronically in the backend of the app.

A mobile app was used to collect data as this was deemed the easiest way to gather responses, while obeying the lockdown restrictions and ensuring the safety of both participants and data collectors. This method of online distribution of a survey and accompanying electronic consent has been used with increasing frequency, particularly during the COVID-19 pandemic for studies with similar methodologies [19,24-27]. 


\section{The Upinion App}

The Upinion messaging and data collection app was developed in 2014 by Upinion, a people-centric research technology company based in the Netherlands, and its use in Southern African Development Community countries is licensed to Opinion Solutions. The app was developed as a way to collect feedback from affected communities in any response effort in order to provide better and more efficient support. It serves as an outlet for those affected by crisis to share their unique problems, needs and solutions, so that nongovernmental organizations have a grass-roots understanding of the situation on the ground, allowing for tailored interventions. This has been used by nonprofit organizations like Oxfam to identify the needs of refugee communities [23], and research institutes like the Wits Reproductive Health and HIV Institute to administer health-related surveys directly via participants' mobile phones [28]. Upinion does not collect personal data, but rather personal data is collected through survey questions and the participant shares this voluntarily. Upinion encrypts all mobile phone numbers and IP addresses in compliance with General Data Protection Regulation and is also ISO/IEC (International Organization for Standardization/International Electrotechnical Commission) 27001 certified. Screenshots of the Upinion app are presented in Figure 1.

Figure 1. The Upinion app.

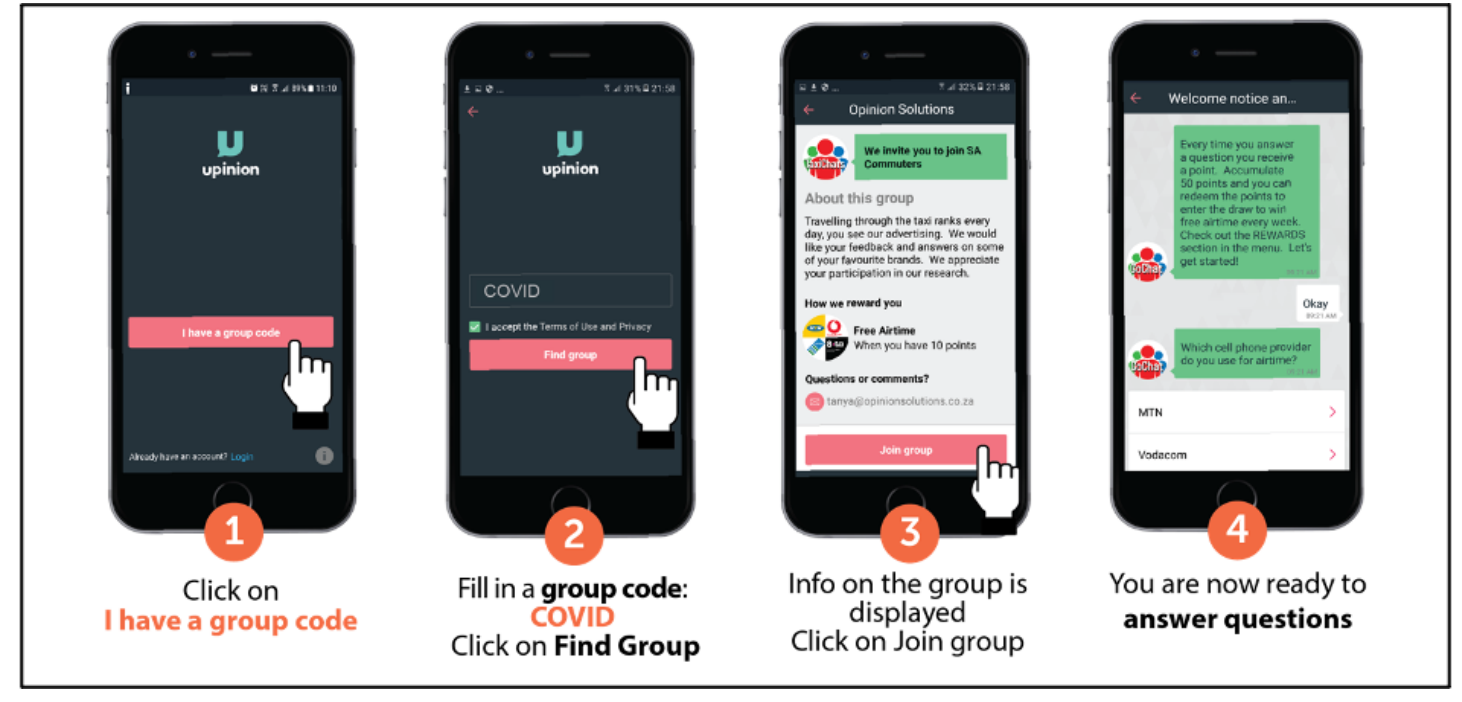

\section{Survey Development}

This survey was adapted from the survey Demographic Data and Structure Knowledge Questionnaire Regarding Prevention of COVID-19, used in a similar study from India [19]. The original questionnaire consists of two sections-the first comprising 8 questions to explore demographic information and the second 10 questions that focused on COVID-19 knowledge. In our survey (Multimedia Appendix 1), we have modified the sections on demographic information and COVID-19 knowledge to reflect the South African context, and a third section was added to explore participants' technology use during the COVID-19 outbreak.

\section{Data Analysis}

Upinion has a built-in dashboard to monitor responses in real time; however, the final data set was exported to Excel (Microsoft Corp) for cleaning and coding, then exported to Stata V.15 (StataCorp) for analysis. Demographic information, technology use, and COVID-19 knowledge questions were all described as frequency and percentages. A mean knowledge score (with standard deviation) was also calculated across all 10 knowledge questions, with a score below 6 considered inadequate knowledge, 6-8 considered moderately adequate knowledge, and a score above 8 considered adequate knowledge [19].

The Pearson chi-square test was used to assess trends of association between outcome variables (COVID-19 knowledge and technology use) and demographic characteristics. Logistic regression models (bivariate [not included in this paper] and multivariable models) were constructed for the outcome variables to control for confounders and identify independent predictors. These predictors were reported as crude (not included in this paper) and adjusted odds ratios (aOR), with $95 \% \mathrm{CI}$ and $P$ values (<.05 was considered significant).

\section{Ethical Consideration and Approval}

Ethics approval was obtained from the University of the Witwatersrand Human Research Ethics Committee (nonmedical) (reference number 200512). Survey respondents did not receive any compensation for participation.

\section{Results}

\section{Demographics}

Participants' demographic data are presented in Table 1. Of the 405 participants, $84(20.74 \%)$ were 28 years or younger, 165 $(40.74 \%)$ were between the ages of 29 and 42 years, 110 $(27.16 \%)$ were between the ages of 43 and 56 years, and 46 $(11.36 \%)$ were 57 years or older. There were $296(73.06 \%)$ females, $320(79.01 \%)$ participants had completed tertiary school education, and $242(59.75 \%)$ were single. A total of 173 $(42.72 \%)$ participants had full-time employment, 74 (18.27\%) were casually employed, 29 (7.16\%) were students, and 129 $(32.85 \%)$ were unemployed. 
Table 1. Demographic characteristics.

\begin{tabular}{|c|c|}
\hline Characteristic & Participants $(\mathrm{N}=405), \mathrm{n}(\%)^{\mathrm{a}}$ \\
\hline \multicolumn{2}{|l|}{ Age (years) } \\
\hline $18-28$ & $84(20.74)$ \\
\hline $29-42$ & 165 (40.74) \\
\hline $43-56$ & $110(27.16)$ \\
\hline$\geq 57$ & $46(11.36)$ \\
\hline \multicolumn{2}{|l|}{ Sex } \\
\hline Female & $296(73.09)$ \\
\hline Male & $109(26.91)$ \\
\hline \multicolumn{2}{|l|}{ Education } \\
\hline Primary school or less & $1(0.25)$ \\
\hline Secondary school & $84(20.74)$ \\
\hline Tertiary school (any) & $320(79.01)$ \\
\hline \multicolumn{2}{|l|}{ Marital status } \\
\hline Married & $163(40.25)$ \\
\hline Single & $242(59.75)$ \\
\hline \multicolumn{2}{|l|}{ Employment status } \\
\hline Casually employed & $74(18.27)$ \\
\hline Full-time employment & $173(42.72)$ \\
\hline Student & $29(7.16)$ \\
\hline Unemployed & $129(31.85)$ \\
\hline
\end{tabular}

${ }^{\mathrm{a}}$ Percentages may not add up to $100.00 \%$ due to rounding.

\section{Technology Use}

A total of $363(89.63 \%)$ participants stated that the lockdown had forced them to use more technology, and the greatest increases in use were for work $(n=140,24.05 \%)$, social media/communication $(\mathrm{n}=133,22.85 \%)$, shopping $(\mathrm{n}=78$, $13.4 \%)$, and news and information $(n=70,12.03 \%)$. Nearly one-third ( $n=127,31.36 \%)$ of participants stated that they were unsure about using technology before the lockdown, with security and privacy issues $(n=46,38.98 \%)$ and unfamiliarity with technology $(n=32,27.12 \%)$ identified as the most common concerns. More than half $(n=209,51.60 \%)$ the participants had positive feelings about the increased forced technology use, while almost all $(n=392,96.79 \%)$ participants stated that they would continue using technology after the lockdown. When asked about information regarding COVID-19, 282 (69.63\%) felt that they had enough information and knowledge, with multimedia $(n=215,53.09 \%)$, mobile phone content $(n=99$, $24.44 \%$ ), and health organizations and professionals ( $\mathrm{n}=91$, $22.47 \%$ ) as their main source of COVID-19 information. Two-thirds $(n=275,67.90 \%)$ of participants stated that they had used their mobile phones for health information before the COVID-19 outbreak, with web searches ( $n=109,26.91 \%)$, social media posts $(\mathrm{n}=58,14.32 \%)$, government and institutional websites $(n=52,12.84 \%)$, and mobile apps $(n=58,14.32 \%)$ serving as their main sources of health information (Table 2). 
Table 2. Technology use.

Technology questions

Participants $(\mathrm{N}=405), \mathrm{n}(\%)^{\mathrm{a}}$

Has the lockdown forced you to use more technology?

Yes

$363(89.63)$

No

42 (10.37)

If yes, what do you use technology for?

$\begin{array}{ll}\text { Job searching } & 33(5.67) \\ \text { Social media/communication } & 133(22.85) \\ \text { Education } & 58(9.97) \\ \text { Shopping } & 78(13.40) \\ \text { Entertainment } & 48(8.25) \\ \text { Work } & 140(24.05) \\ \text { News and information } & 70(12.03) \\ \text { Banking } & 16(2.75) \\ \text { Religion } & 6(1.03)\end{array}$

Were you unsure about using technology/online methods before?

Yes

127 (31.36)

No

278 (68.64)

If yes, what made you feel uncomfortable?

Security/privacy issues

46 (38.98)

Unfamiliar with technology

32 (27.12)

Lack of personal connection/accountability

16 (13.56)

Cost of data and devices

$10(8.47)$

Reliability issues

14 (11.86)

How do you feel about the increased forced use of technology?

Positive feelings

Neutral/mixed feelings

$129(31.85)$

Negative feelings

67 (16.54)

Will you continue to use technology after the lockdown?

Yes

$392(96.79)$

No

13 (3.21)

Do you have enough information/knowledge regarding COVID-19?

Yes

No

$123(30.37)$

What is your main source of information on COVID-19?

Health organizations and professionals

Mobile phone content

$99(24.44)$

Multimedia (radio, television, newspaper)

$215(53.09)$

Have you used your mobile phone for health information before the COVID-19 outbreak?

Yes

No

$130(32.10)$

If yes, what was your main source of health information?

Email

Government/institutional websites 


\begin{tabular}{ll}
\hline Technology questions & ${\text { Participants }(\mathrm{N}=405), \mathrm{n}(\%)^{\mathrm{a}}}^{\mathrm{a}}$ \\
\hline Messaging platforms (WhatsApp, SMS) & $17(4.20)$ \\
Mobile apps & $38(9.38)$ \\
Social media posts & $58(14.32)$ \\
Web searches (Google) & $109(26.91)$ \\
\hline
\end{tabular}

${ }^{\mathrm{a}}$ Percentages may not add up to $100.00 \%$ due to rounding.

Logistic regression analysis identified relationships between demographics and 4 technology use variables (Multimedia Appendix 2). When asked if the lockdown had forced participants to use more technology, participants with a tertiary school education were 2.5 times more likely to increase their technology use than those with a primary or secondary school education (aOR 2.580; 95\% CI 1.212-5.489, $P=.01$ ), and full-time employees were also less likely to increase their technology use compared to those casually employed (aOR $0.275 ; 95 \%$ CI $0.078-0.966, P=.04)$.

Regarding the main source of COVID-19 information, multimedia, health organizations and professionals, and mobile phone content all had demographic associations. Tertiary school graduates were less likely to use multimedia as their main source of COVID-19 information compared to those with primary or secondary school education (aOR 0.536; 95\% CI 0.319-0.900, $P=.02$ ). Multimedia was almost 2 times more likely to be the main source of information in respondents aged 29-42 years, when compared to those younger than 29 years (aOR 1.862; $95 \%$ CI 1.062-3.378, $P=.04$ ). Single participants were less likely to use health organizations and professionals (aOR 0.537; 95\% CI $0.318-0.906, P=.02)$ as their main source of COVID-19 information. Mobile phone content was also associated with age, with the 57-70-year-old group being least likely (aOR $0.339 ; 95 \%$ CI $0.128-0.896, P=.03$ ) to use their mobile as the main source of health information compared to those younger than 29 years of age.

The associations seen among participants who responded that they had enough information or knowledge about COVID-19 included age, being male, being single, and having a tertiary education.

The 57-70-year-old group were approximately 6 times (aOR 5.661; 95\% CI $1.894-16.925, P=.002)$ more likely to have adequate information compared to those younger than 29 years of age. Males were almost twice as likely (aOR 1.892; 95\% CI 1.094-3.272, $P=.02$ ) than females to have enough COVID-19 information as were those having a tertiary school education (aOR 1.885; 95\% CI 1.111-3.198, $P=.02$ ) over those with a secondary education or lower, while single participants were less likely (aOR 0.509 ; 95\% CI $0.297-0.873, P=.01$ ) to have adequate information.

The oldest age group and students were the least likely to use their phone for health information prior to the pandemic (older adults: aOR $0.184 ; 95 \%$ CI 0.075-0.449, $P<.001$; students: aOR $0.277 ; 95 \%$ CI $0.103-0.740, P=.01)$.

\section{COVID-19 Knowledge}

When asked about COVID-19, 358 (88.40\%) participants correctly identified it as a contagious respiratory virus, and 392 (96.79\%) correctly stated that it was transmitted through respiratory droplets. Over three-quarters $(n=319,78.77 \%)$ of participants correctly chose all the ways that the virus could be spread; the rest thought it was only spread by coughing or sneezing $(n=52,18.84 \%)$, by touching objects that have COVID-19 droplets on them $(n=17,4.2 \%)$, or through close contact with an infected individual $(n=16,3.95 \%)$. All of the common COVID-19 symptoms (cough, sore throat, fever, and shortness of breath) were correctly identified by 379 (93.58\%) participants; the same percentage correctly identified all encouraged prevention techniques (avoid touching one's face, avoid contact with sick people, and wash hands thoroughly). When asked about handwashing duration, 20 seconds was correctly selected by the majority $(n=340,83.95 \%)$. For the question on how to stop the spread of COVID-19, 368 (90.86\%) correctly chose social distancing, self-isolation, and regular handwashing as their response, and when asked how to stop the chance of spreading the virus, $383(94.57 \%)$ correctly chose coughing and sneezing into their elbow, social distancing and self-isolation, and regular handwashing as their response. Most participants $(n=308,76.05 \%)$ correctly stated that they would call the emergency hotline or WhatsApp support line if they thought they had COVID-19 symptoms, although 79 (19.51\%) incorrectly stated that they would rush to the nearest hospital for testing. Lastly, practicing social distancing, self-isolation, and washing one's hands thoroughly were all correctly identified by $369(91.11 \%)$ participants as the key to prevent the spread of COVID-19 (Table 3). 
Table 3. Structured COVID-19 questionnaire.

\begin{tabular}{ll}
\hline COVID-19 questions & Participants $(\mathrm{N}=405), \mathrm{n}(\%)$
\end{tabular}

What is the novel coronavirus (COVID-19)?

It is a bioweapon

$11(2.72)$

It is a sexually transmitted infection

It is a very contagious respiratory virus

It is just another term for the common cold

It is transmitted through respiratory droplets

What are the transmission routes of COVID-19?

It is transmitted by eating Chinese food

It is transmitted through direct blood contact

It is transmitted through respiratory droplets

It is transmitted through sexual intercourse

$3(0.74)$

How can COVID-19 be spread?

By touching objects that have COVID-19 respiratory droplets

Through close contact with an infected individual

Through coughing or sneezing

52 (12.84)

All of the above

(Blank)

What are the signs and symptoms of COVID-19?

Cough and sore throat

Fever

Shortness of breath

All of the above

The coronavirus can be prevented by

Avoid touching your face

Avoiding contact with sick people

$7(1.73)$

Wash your hands thoroughly

All of the above

Wash your hands with soap or sanitizer for at least

5 seconds

10 seconds

20 seconds

$340(83.95)$

1 minute

To stop the spread of the coronavirus, you should

Practice social distancing

Practice social distancing and wash your hands thoroughly

Self-isolate

Self-isolate and practice social distancing

Wash your hands thoroughly

All of the above

How can you stop the chances of spreading the coronavirus? 


\begin{tabular}{|c|c|}
\hline COVID-19 questions & Participants $(\mathrm{N}=405), \mathrm{n}(\%)^{\mathrm{a}}$ \\
\hline Self-isolate and practice social distancing & $13(3.21)$ \\
\hline Wash your hands thoroughly & $5(1.23)$ \\
\hline All of the above & $383(94.57)$ \\
\hline \multicolumn{2}{|c|}{ What will you do if you suspect that you have symptoms of COVID-19? } \\
\hline Call the emergency hotline or WhatsApp support line & $308(76.05)$ \\
\hline Go to the pharmacy to get medication & $9(2.22)$ \\
\hline Rush to the nearest hospital for testing & $79(19.51)$ \\
\hline Stay in close physical contact with friends/family for support & $8(1.98)$ \\
\hline (Blank) & $1(0.25)$ \\
\hline \multicolumn{2}{|l|}{ What is the key to prevent the spread of COVID-19? } \\
\hline Practice social distancing & $10(2.47)$ \\
\hline Self-isolate & $18(4.44)$ \\
\hline Wash your hands thoroughly & $7(1.73)$ \\
\hline All of the above & $369(91.11)$ \\
\hline \multicolumn{2}{|l|}{ Total knowledge score } \\
\hline Inadequate (score $\leq 5$ ) & 19 (4.69) \\
\hline Moderately adequate $($ score $=6,7)$ & $51(12.59)$ \\
\hline Adequate (score $\geq 8$ ) & $335(82.72)$ \\
\hline
\end{tabular}

${ }^{\mathrm{a}}$ Percentages may not add up to $100.00 \%$ due to rounding.

Overall, the mean knowledge score was 8.8 (SD 1.53). There were only $19(4.69 \%)$ participants with inadequate knowledge, $51(12.59 \%)$ with moderately adequate knowledge, and 335 $(82.72 \%)$ with adequate knowledge (Table 3$)$.

Logistic regression analysis identified relationships between demographics and 4 COVID-19 knowledge variables. Males were less likely to identify the correct transmission routes of COVID-19 (aOR 0.216; 95\% CI 0.063-0.744, $P=.02$ ) than females, while those with a tertiary education were 4 times more likely to correctly identify the routes (aOR $4.414 ; 95 \% \mathrm{CI}$ $1.308-14.900, P=.02$ ) than those with only primary or secondary education. Tertiary school graduates were also 2 times more likely to identify how to stop the spread of the virus (aOR 2.215; 95\% CI 1.041-4.714, $P=.04$ ), compared to participants with only primary or secondary education. Single participants were less likely to identify the signs and symptoms of COVID-19 (aOR $0.182 ; 95 \%$ CI $0.052-0.631, P=.01$ ) than married participants. The 43-56 years age category was 4 times more likely to identify how COVID-19 can be prevented (aOR 3.987; 95\% CI 1.011-15.718, $P=.048$ ) compared to those under 29 years of age (Multimedia Appendix 3).

Lastly, association analyses conducted separately between demographics and the outcome variables (COVID-19 knowledge scores and technology use) only identified a significant relationship in participants $\geq 57$ years being 2.6 times more likely to obtain a knowledge score of 10 (aOR 2.60; 95\% CI 1.1-6.0, $P=.03$ ) when compared to participants 28 years and under.

\section{Discussion}

\section{Principal Findings}

This study is the first to describe how South Africans interact with technology and consume health information during the current COVID-19 outbreak. Our findings were in line with a similar study from India [19]. Multimedia was the main source of COVID-19 information for both countries (India: $\mathrm{n}=57$, $55.4 \%$ vs South Africa: $\mathrm{n}=215,53.09 \%$ ), followed by the internet in India $(n=22,21.4 \%)$ and mobile phone content in South Africa $(n=99,24.44 \%)$. Despite more people in India stating that they had adequate COVID-19 information (India: $\mathrm{n}=98,95.1 \%$ vs South Africa: $\mathrm{n}=282,69.63 \%$ ), the South African mean knowledge score of 8.8 was slightly higher than that of India (8.01). The South African study also showed that the lockdown has forced the majority of participants to increase their technology use and these findings are in line with similar increases in technology use from around the world [5-7,29-31]. Participants with a tertiary school education were more likely to increase their technology use than those with less education, who were less likely to use multimedia as their main source of COVID-19 information. This is in line with a study from sub-Saharan Africa, which showed that the positive effects of mobile phone use is diminished by poor primary education [32]. However, in addition, these findings may be explained by socioeconomic factors associated with more education, as college graduates earn higher wages and are better equipped to cope with economic shocks [33]. Full-time employees were less likely to increase their technology use compared to those who were causally employed, although this may be due to a higher 
baseline of technology use for full-time employees due to the growing demands of the knowledge economy [34].

The rise in South African technology use has also been validated by the nation's data usage, which increased by more than one-third over the first few days of the lockdown [35]. This increase in technology use led the government to quickly digitize education through a combination of free electronic readers and zero-rated educational apps and websites. This has allowed schools to move to an online curriculum, which has facilitated the return to studies via home-based schooling for many students, by mid-March 2020 [29]. Similarly, apps and websites are also being used by the National Department of Health to relay COVID-19 information to the public $[3,13,14]$; however, there are many other online sources for COVID-19 information.

Government or institutional websites [3,4,13,14] publish evidence-based information and fact check their findings; however, more participants stated that their main mobile source of health information was web searches or social media posts. Unfortunately, web searches and social media posts are not regulated, and the sharing of misinformation has created an infodemic surrounding COVID-19 [8,25]. This misinformation includes false news articles, conspiracy theories surrounding the virus creation, ineffective home remedies for treatment, and downplaying of the need for prevention control, such as social distancing and mask use. The propagation of this misinformation can actually present a health risk and may undermine the countermeasures implemented by governments and credible institutions [8,36]. Despite a high overall knowledge score, misinformation may have played a role in this study, as two questions (How COVID-19 can be spread? and What will you do if you suspect that you have symptoms of COVID-19?) scored below adequate. These questions may identify knowledge gaps where increased outreach is needed to educate the population, especially for the second question, where 79 (19.51\%) participants stated that they would rush to the nearest hospital for testing instead of calling the emergency hotline or WhatsApp support line for further instructions. There are a number of documented ways to engage users on mobile platforms, and the government can use them to dispel misinformation by guiding people to accurate information sources. Social media outreach, with dialogue loops, is a particularly effective way to engage with individuals, and this type of social media outreach can be tailored with specific messages that target specific subpopulations [37,38].

Misinformation may have disproportionately affected participants under the age of 29 years, especially when compared to those above 57 years. The older group was less likely to use their mobile as the main source of health information, yet they were 6 times more likely to have enough COVID-19 information, and 2.6 times more likely to obtain a knowledge score of 10. In South Africa, youth under 30 years are almost $20 \%$ more likely to use their phone to access the internet than their parents, which would expose the younger age group to more online misinformation than the oldest age group [39]. Single participants were less likely to use health organizations and professionals as their source of COVID-19 information, and not using a trusted source may have also led to misinformation, as they were less likely to have enough COVID-19 information and correctly identify COVID-19 signs and symptoms. Having enough COVID-19 information may not be a true indicator of knowledge though since males were twice as likely to say they had enough COVID-19 information but were less likely to identify the correct routes of COVID-19 transmission.

This study has also reiterated some known barriers to mobile use in South Africa, such as security and privacy issues, unfamiliarity with technology, and data costs. Due to an increase in data usage, some local networks have temporarily lowered data costs [35], but long-term affordable data plans are required to ensure equitable mobile usage for the duration of this lockdown and in the future [40]. Security and privacy issues have been well documented in South Africa, especially for mHealth platforms $[22,41,42]$. However, previous studies have shown that personal identification number (PIN)-protected mobile platforms for delivering sensitive health information are feasible and acceptable in South Africa [42,43]. Furthermore, a Japanese study that investigated online consumption suggests that the process of making online purchases for the first time during the lockdown has facilitated people becoming familiar with technology, thus alleviating some perceived barriers [44]. This information provides context to the 392 (96.8\%) participants who stated they will continue to use technology after the pandemic. However, follow-up studies must be conducted to quantify this.

\section{Limitations}

A selection bias may be present due to the device and data requirements needed to access this survey, which was conducted online via a convenience sample. As this survey was adapted from a pre-existing survey, it was not validated or pilot tested in South Africa before this study. Furthermore, participants were asked to self-report their technology use, and no measurements were taken to validate these statements.

\section{Conclusion}

This study has shown that the COVID-19 lockdown has forced many people to increase technology use, and almost all participants will continue to use technology post lockdown. Increased technology use was seen across a variety of fields; however, well-known barriers were cited, including privacy and security concerns, unfamiliarity with technology, and data costs. This population showed high COVID-19 knowledge, but the use of web searches and social media posts, instead of government and institutional websites, provides the potential for health misinformation about COVID-19 to be spread. This was particularly evident in some subdemographic groups, including participants under 29 years, single participants, participants without tertiary education, and males. These groups should be targeted with further education and preventative measures. 


\section{Acknowledgments}

The authors would like to thank all of the survey participants.

\section{Conflicts of Interest}

None declared.

\section{Multimedia Appendix 1}

Technology use during the COVID-19 lockdown survey.

[DOCX File, 22 KB-Multimedia Appendix 1]

\section{Multimedia Appendix 2}

Logistic regressions of technology use.

[DOCX File , $20 \mathrm{~KB}-$ Multimedia Appendix 2]

\section{Multimedia Appendix 3}

Logistic regressions of COVID-19 knowledge. [DOCX File, 19 KB-Multimedia Appendix 3]

\section{References}

1. WHO Director-General's opening remarks at the media briefing on COVID-19-11 March 2020. World Health Organization. 2020 Mar 11. URL: https://www.who.int/dg/speeches/detail/who-director-general-s-opening-remarks-at-the-mediabriefing-on-covid-19---11-march-2020 [accessed 2021-05-12]

2. President Cyril Ramaphosa: Escalation of measures to combat Coronavirus COVID-19 pandemic. South African Government. 2020 Mar 23. URL: https://www.gov.za/speeches/president-cyril-ramaphosa-escalation-measures-combatcoronavirus-covid-19-pandemic-23-mar [accessed 2021-05-12]

3. COVID-19. National Department of Health, South Africa. 2020. URL: http://health.gov.za/covid19/index.html

4. Coronavirus disease (COVID-19) Situation Report - 209. World Health Organization. 2020 Aug 17. URL: https://www. who.int/docs/default-source/coronaviruse/situation-reports/20200816-covid-19-sitrep-209.pdf?sfvrsn=5dde1ca2 2 [accessed 2021-05-12]

5. Depoux A, Martin S, Karafillakis E, Preet R, Wilder-Smith A, Larson H. The pandemic of social media panic travels faster than the COVID-19 outbreak. J Travel Med 2020 May 18;27(3) [FREE Full text] [doi: 10.1093/jtm/taaa031] [Medline: $\underline{32125413]}$

6. Gao J, Dai J, Zheng P, Chen H. Mental health problems and social media exposure during COVID-19 outbreak. SSRN Journal. Preprint posted online Feb 20, 2020 [FREE Full text] [doi: 10.2139/ssrn.3541120]

7. Koetsier J. Coronavirus boosted mobile app spend in Q1 to the highest in history. Forbes. 2020 Apr 2. URL: https://www. forbes.com/sites/johnkoetsier/2020/04/02/coronavirus-impact-houseparty-installs-up-735x-app-use-up-20-app-store-spendhighest-in-history/?sh=31ab858cae58 [accessed 2020-04-16]

8. Cinelli M, Quattrociocchi W, Galeazzi A, Valensise CM, Brugnoli E, Schmidt AL, et al. The COVID-19 social media infodemic. Sci Rep 2020 Oct 06;10(1):16598 [FREE Full text] [doi: 10.1038/s41598-020-73510-5] [Medline: 33024152]

9. Cho H, Ippolito D, Yu Y. Contact Tracing Mobile Apps for COVID-19: Privacy Considerations and Related Trade-offs. arXiv. Preprint posted online Mar 25, 2020 [FREE Full text]

10. Hollander JE, Carr BG. Virtually Perfect? Telemedicine for Covid-19. N Engl J Med 2020 Apr 30;382(18):1679-1681. [doi: 10.1056/NEJMp2003539] [Medline: 32160451]

11. The World Health Organization launches WHO Health Alert on WhatsApp. WhatsApp. URL: https://www.whatsapp.com/ coronavirus/who [accessed 2020-04-05]

12. Wong JEL, Leo YS, Tan CC. COVID-19 in Singapore-Current Experience: Critical Global Issues That Require Attention and Action. JAMA 2020 Apr 07;323(13):1243-1244. [doi: 10.1001/jama.2020.2467] [Medline: 32077901]

13. National Department of Health, South Africa. 2020. URL: https://sacoronavirus.co.za [accessed 2020-04-07]

14. COVID-19 / Novel Coronavirus. South African Government. 2020. URL: https://www.gov.za/Coronavirus [accessed 2020-04-07]

15. Jahanbin K, Rahmanian V. Using Twitter and web news mining to predict COVID-19 outbreak. Asian Pac J Trop Med 2020;13(8):378-380 [FREE Full text] [doi: 10.4103/1995-7645.279651]

16. Li C, Chen L, Chen X, Zhang M, Pang CP, Chen H. Retrospective analysis of the possibility of predicting the COVID-19 outbreak from Internet searches and social media data, China, 2020. Euro Surveill 2020 Mar;25(10):2000199 [FREE Full text] [doi: 10.2807/1560-7917.ES.2020.25.10.2000199] [Medline: $\underline{\text { 32183935] }}$ 
17. Niler E. An AI Epidemiologist Sent the First Warnings of the Wuhan Virus. Wired. 2020 Jan 25. URL: https://www. wired.com/story/ai-epidemiologist-wuhan-public-health-warnings/ [accessed 2020-04-06]

18. Nayar KR, Sadasivan L, Shaffi M, Vijayan B, P Rao A. Social Media Messages Related to COVID-19: A Content Analysis. SSRN Journal. Preprint posted online Mar 25, 2020 [FREE Full text] [doi: 10.2139/ssrn.3560666]

19. Ranjan R, Ranjan G. Knowledge Regarding Prevention of Novel Coronavirus (COVID-19): An Electronic Cross-Sectional Survey among Selected Rural Community. International Journal of Trend in Scientific Research and Development 2020;4(3):422-426 [FREE Full text]

20. Bloomfield GS, Vedanthan R, Vasudevan L, Kithei A, Were M, Velazquez EJ. Mobile health for non-communicable diseases in Sub-Saharan Africa: a systematic review of the literature and strategic framework for research. Global Health 2014 Jun 13;10(1):49 [FREE Full text] [doi: 10.1186/1744-8603-10-49] [Medline: 24927745]

21. The Mobile Economy: Sub-Saharan Africa 2017. GSMA Intelligence. 2017. URL: www.gsmaintelligence.com/research/ ?file=7bf3592e6d750144e58d9dcfac6adfab\&download [accessed 2021-05-12]

22. Vaportzis E, Clausen MG, Gow AJ. Older Adults Perceptions of Technology and Barriers to Interacting with Tablet Computers: A Focus Group Study. Front Psychol 2017 Oct 04;8:1687 [FREE Full text] [doi: 10.3389/fpsyg.2017.01687] [Medline: 29071004]

23. Amplify voices in crisis situations. Upinion. URL: https://upinion.com [accessed 2021-04-08]

24. Geldsetzer P. Knowledge and Perceptions of COVID-19 Among the General Public in the United States and the United Kingdom: A Cross-sectional Online Survey. Ann Intern Med 2020 Jul 21;173(2):157-160 [FREE Full text] [doi: 10.7326/M20-0912] [Medline: 32196071]

25. Pennycook G, McPhetres J, Zhang Y, Rand D. Fighting COVID-19 Misinformation on Social Mediaxperimental Evidence for a Scalable Accuracy-Nudge Intervention. PsyArXiv Preprints. Preprint posted online March 17, 2020. [doi: 10.31234/osf.io/uhbk9]

26. Lunt H, Connor S, Skinner H, Brogden G. Electronic informed consent: the need to redesign the consent process for the digital age. Intern Med J 2019 Jul 11;49(7):923-929. [doi: 10.1111/imj.14339] [Medline: 31295775]

27. Rothwell E, Wong B, Rose NC, Anderson R, Fedor B, Stark LA, et al. A randomized controlled trial of an electronic informed consent process. J Empir Res Hum Res Ethics 2014 Dec 02;9(5):1-7 [FREE Full text] [doi: 10.1177/1556264614552627] [Medline: 25747685]

28. Majam M, Venter WDF. Taxi rank baseline Sexual Health HIV Survey (HSTAR006) - Protocol. Johannesburg, South Africa: Wits RHI, University of Witwatersrand; Jan 8, 2018.

29. Mhlanga D, Moloi T. COVID-19 and the Digital Transformation of Education: What Are We Learning on 4IR in South Africa? Education Sciences 2020 Jul 09;10(7):180. [doi: 10.3390/educsci10070180]

30. Semuels A. Many Companies Won't Survive the Pandemic. Amazon Will Emerge Stronger Than Ever. The Times. 2020 Jul 28. URL: https://time.com/5870826/amazon-coronavirus-jeff-bezos-congress/ [accessed 2020-10-07]

31. Koeze EN. The virus changed the way we internet. New York Times. 2020 Apr 7. URL: https://www.nytimes.com/interactive/ 2020/04/07/technology/coronavirus-internet-use.html [accessed 2020-10-07]

32. Asongu SA, Odhiambo NM. Basic formal education quality, information technology, and inclusive human development in sub - Saharan Africa. Sustainable Development 2018 Nov 28;27(3):419-428. [doi: 10.1002/sd.1914]

33. World Bank Education Overview : Higher Education (English). The World Bank. 2018. URL: http://documents. worldbank.org/curated/en/610121541079963484/World-Bank-Education-Overview-Higher-Education [accessed 2021-05-12]

34. Baum S, Ma J, Payea K. Education Pays, 2013: The Benefits of Higher Education for Individuals and Society. Trends in Higher Education Series. College Board 2013:1-48 [FREE Full text]

35. Chen D. Coronavirus: Overcoming the Educational Digital Divide in South Africa. Tech Financials. 2020 Apr 2. URL: https://www.techfinancials.co.za/2020/04/02/coronavirus-overcoming-the-educational-digital-divide-in-south-africa/ [accessed 2021-10-08]

36. Allington D, Duffy B, Wessely S, Dhavan N, Rubin J. Health-protective behaviour, social media usage and conspiracy belief during the COVID-19 public health emergency. Psychol Med 2020 Jun 09:1-7. [doi: 10.1017/s003329172000224x]

37. Poushter J. Smartphone Ownership and Internet Usage Continues to Climb in Emerging Economies. Pew Research Center. 2016 Feb 22. URL: https://www.pewresearch.org/global/2016/02/22/smartphone-ownership-and-internet-usagecontinues-to-climb-in-emerging-economies/ [accessed 2018-10-22]

38. Chen Q, Min C, Zhang W, Wang G, Ma X, Evans R. Unpacking the black box: How to promote citizen engagement through government social media during the COVID-19 crisis. Comput Human Behav 2020 Sep;110:106380 [FREE Full text] [doi: 10.1016/j.chb.2020.106380] [Medline: 32292239]

39. Gough A, Hunter RF, Ajao O, Jurek A, McKeown G, Hong J, et al. Tweet for Behavior Change: Using Social Media for the Dissemination of Public Health Messages. JMIR Public Health Surveill 2017 Mar 23;3(1):e14 [FREE Full text] [doi: 10.2196/publichealth.6313] [Medline: 28336503]

40. Fischer AE, Sebidi J, Barron P, Lalla-Edward ST. The MomConnect Nurses and Midwives Support Platform (NurseConnect): A Qualitative Process Evaluation. JMIR Mhealth Uhealth 2019 Feb 13;7(2):e11644 [FREE Full text] [doi: 10.2196/11644] [Medline: 30758298] 
41. Venter WDF, Fischer A, Lalla-Edward ST, Coleman J, Lau Chan V, Shubber Z, et al. Improving Linkage to and Retention in Care in Newly Diagnosed HIV-Positive Patients Using Smartphones in South Africa: Randomized Controlled Trial. JMIR Mhealth Uhealth 2019 Apr 02;7(4):e12652 [FREE Full text] [doi: 10.2196/12652] [Medline: $\underline{30938681]}$

42. DiAndreth L, Krishnan N, Elf JL, Cox S, Tilchin C, Nthulana M, et al. Formative research for an mHealth program to improve the HIV care continuum in South Africa. AIDS Care 2020 Jun 12;32(6):744-748. [doi:

10.1080/09540121.2019.1640850] [Medline: 31298566]

43. Maraba N, Hoffmann CJ, Chihota VN, Chang LW, Ismail N, Candy S, et al. Using mHealth to improve tuberculosis case identification and treatment initiation in South Africa: Results from a pilot study. PLoS One 2018 Jul 3;13(7):e0199687 [FREE Full text] [doi: 10.1371/journal.pone.0199687] [Medline: 29969486]

44. Watanabe T, Yuki O. Online Consumption During the COVID-19 Crisis: Evidence from Japan. Working Paper Series No.023. Tokyo, Japan: University of Tokyo; 2020. URL: https://www.centralbank.e.u-tokyo.ac.jp/wp-content/uploads/ 2020/06/cb-wp023.pdf [accessed 2021-05-12]

\author{
Abbreviations \\ aOR: adjusted odds ratio \\ IEC: International Electrotechnical Commission \\ ISO: International Organization for Standardization \\ mHealth: mobile health
}

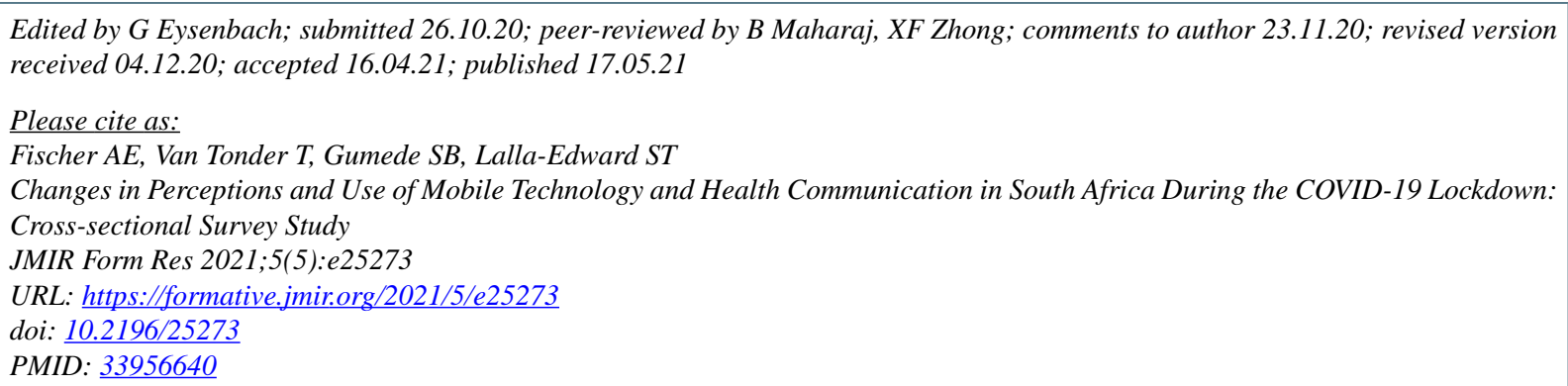

(C)Alex Emilio Fischer, Tanya Van Tonder, Siphamandla B Gumede, Samanta T Lalla-Edward. Originally published in JMIR Formative Research (https://formative.jmir.org), 17.05.2021. This is an open-access article distributed under the terms of the Creative Commons Attribution License (https://creativecommons.org/licenses/by/4.0/), which permits unrestricted use, distribution, and reproduction in any medium, provided the original work, first published in JMIR Formative Research, is properly cited. The complete bibliographic information, a link to the original publication on https://formative.jmir.org, as well as this copyright and license information must be included. 